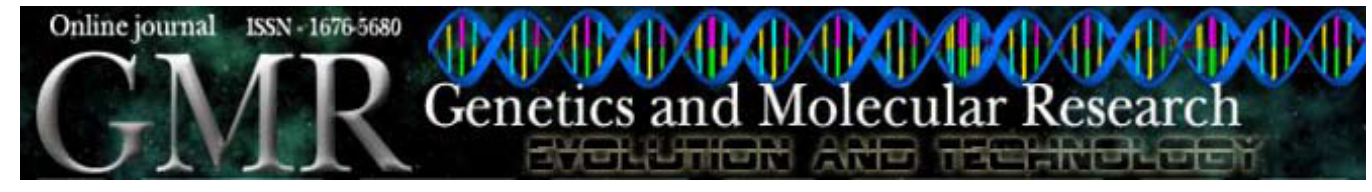

\title{
Molecular identification of Greek olive (Olea europaea) cultivars based on microsatellite loci
}

\author{
K. Roubos $^{1,2}$, M. Moustakas ${ }^{1}$ and F.A. Aravanopoulos ${ }^{3}$ \\ ${ }^{1}$ Department of Botany, School of Biology, Faculty of Sciences, \\ Aristotle University of Thessaloniki, Thessaloniki, Greece \\ ${ }^{2}$ Molecular Biology Laboratory, School of Agricultural Technology, \\ Alexander Technological Institute of Thessaloniki, Sindos, Greece \\ ${ }^{3}$ Laboratory of Forest Genetics and Forest Tree Breeding, \\ Faculty of Forestry and Natural Environment, \\ Aristotle University of Thessaloniki, Thessaloniki, Greece \\ Corresponding author: F.A. Aravanopoulos \\ E-mail: aravanop@for.auth.gr \\ Genet. Mol. Res. 9 (3): 1865-1876 (2010) \\ Received May 20, 2010 \\ Accepted July 15, 2010 \\ Published September 21, 2010 \\ DOI 10.4238/vol9-3gmr916
}

\begin{abstract}
Olea europaea is one of the oldest species of domesticated trees. We used microsatellite markers for fingerprinting and for evaluation of genetic similarity and structure of 26 Greek olive cultivars, which cover most of the olive cultivation regions of Greece, including previously undescribed denominations from northern Greece. Eighty-one alleles were revealed with six SSR loci that were selected as most informative of 10 SSR primers that were initially investigated. The number of alleles per locus varied from 7 to 20 (mean, 13.5). Heterozygosity ranged from 0.240 at locus DCA-3 to 0.826 at locus UDO99-9, with a mean value of 0.600. Analysis of 104 trees representing 26 denominations (four trees per denomination) revealed 26 distinct SSR profiles, indicating 26 olive cultivars; no intracultivar variability was observed. Genetic and geographic distances were not significantly correlated, based on the Mantel test. These SSR loci
\end{abstract}


allowed unequivocal identification of all the cultivars and will be useful for future breeding and olive germplasm management efforts.

Key words: Olea europaea; Molecular markers; SSR; DNA fingerprinting

\section{INTRODUCTION}

An important part of everyday life in ancient Mediterranean civilizations, the olive (Olea europaea) remains one of the most abundantly cultivated tree species throughout the Mediterranean basin. Olive trees are cultivated in a variety of climates, from the coastline of the Mediterranean basin to interior regions with a cooler climate (Bracci et al., 2009).

Olive production throughout the world uses more than 1275 cultivars; most cultivars have been identified in southern European countries, including 538 in Italy, 183 in Spain, 88 in France, and 52 in Greece (Sarri et al., 2006; Ipec et al., 2009). Greece holds third place in world olive production, with more than 117 million olive trees; $80 \%$ of Greek orchard land is devoted to olive culture.

Olive trees are predominantly allogamous (Díaz et al., 2006a), which leads to high levels of heterozygosity and DNA polymorphisms among cultivars (Rallo et al., 2000). The wealth of genetic variability, coupled with considerable confusion in olive cultivar nomenclature, makes evaluation and characterization of olive genetic resources necessary. DNA fingerprinting is recognized as very important, since both olive productivity and oil quality are traits inherent to varieties. It is presumed that crosses between wild local olive trees and introduced selected cultivars have led to new cultivars (Besnard et al., 2001b). Olea europaea is a highly variable species, with hundreds of denominations, cultivated mainly in the Mediterranean basin (Banilas et al., 2003).

Until recent years, cultivar identification has been based on morphological and agronomic traits. However, the recognition of olive cultivars based on phenotypic characters is often problematic, especially at the early stages of tree development (Banilas et al., 2003). This has led to great confusion and uncertainty about the current status of olive germplasm in many countries, including Greece. The ability to discriminate olive cultivars and estimate genetic variability is important for successful breeding programs and improved management of genetic resources (Owen et al., 2005). The use of molecular markers to manage olive germplasm is particularly advantageous, due to the fact that the olive has an exceptionally long juvenile period (Montemurro et al., 2005). Many of the main Greek olive cultivars are identified using RAPD (Nikoloudakis et al., 2003; Hagidimitriou et al., 2005), AFLP (Hagidimitriou et al., 2005; Owen et al., 2005) and ISSR markers (Terzopoulos et al., 2005).

Microsatellite markers (simple sequence repeats, SSRs) are a powerful tool for olive cultivar identification because they are transferable, co-dominant, highly polymorphic, widely distributed along the genome, and easily reproducible (Rallo et al., 2000). SSRs have proven to be efficient for cultivar characterization, and several loci have been developed for O. europaea (Rallo et al., 2000; Sefc et al., 2000; Carriero et al., 2002; Cipriani et al., 2002; De la Rosa et al., 2002; Díaz et al., 2006b; Baldoni et al., 2009). The use of SSRs to characterize olive cultivars could become an efficient tool for germplasm conservation and management strategies.

The main areas of olive cultivation in Greece are the south and central provinces 
of the country, the coastline regions and the islands. Currently, olive cultivation is expanding rapidly in the northern part of Greece. A number of olive varieties have been used in inland areas of northern Greece during the past 600 years, but they remain largely unexploited. The recent rapid expansion of olive cultivation in this area makes these varieties particularly important. Cultivated areas in Northern Greece use both traditional cultivars (Koroneiki, Megaritiki, Kalamon) and local denominations (Maronias, Chondrolia Chalkidikis, Galatistas, Petrolia Serron, Lefkolia Serron, Arvanitolia Serron, Pierias). Study of genetic resources and discrimination of Greek olive denominations are particularly important for efforts to preserve biodiversity and maintain the advantages of local varieties. Furthermore, genotype information can assist breeding programs and help clarify cases of homonymy and synonymy in Greek olive cultivars.

We utilized SSRs to fingerprint and assess the genetic diversity of olive cultivars that represent almost all $O$. europaea cultivation range in Greece. Previously undescribed local denominations of Northern Greece were included in addition to traditional Greek olive cultivars. The hypothesis that northern Greek denominations represent new cultivars and form a distinctive genetic group within Greek olive cultivars was tested.

\section{MATERIAL AND METHODS}

\section{Plant material}

Samples were collected before the flowering period in May 2007 from the olive cultivar collection of the Alexander Technological Educational Institute of Thessaloniki. One hundred and four individuals were sampled, representing 26 Greek olive denominations (four individuals per denomination) that included seven denominations from north Greece and 19 traditional Greek olive cultivars (Table 1, Figure 1; Kostelenos, 2006). All trees displayed the typical morphological characteristics (i.e., leaf size and shape, fruit shape) of the cultivars they represented.

\section{DNA isolation}

DNA was extracted from fresh leaves according to Sefc et al. (2000) with minor modifications. After phenol:chloroform:isoamyl alcohol extraction, the supernatant was subjected to two ether extractions to remove residual phenol.

\section{PCR amplification}

Six SSR loci (Table 2) were selected of 10 that were originally investigated, from three groups of SSR primers: DCA (Sefc et al., 2000), UDO99 (Cipriani et al., 2002) and EMO (De La Rosa et al., 2002). Selection was made based on degree of polymorphism, as well as clear, stable and repeatable amplified DNA fragments. Polymerase chain reactions (PCRs) were performed in a final volume of $20 \mu \mathrm{L}$, containing 1X PCR buffer (Invitrogen), $0.2 \mathrm{mM}$ of each dNTP (Invitrogen), $1.5 \mathrm{mM} \mathrm{MgCl}, 0.2 \mathrm{mM}$ of each primer (Invitrogen), $20 \mathrm{ng}$ genomic DNA and $1 \mathrm{U}$ Taq Polymerase enzyme (Invitrogen). Amplification was performed in a Mastercycler ${ }^{\circledR}$ thermal cycler (Eppendorf). The temperature profile was the following: initial denaturation for $5 \mathrm{~min}$ at $95^{\circ} \mathrm{C} ; 35$ cycles of three repetitive steps consisting of a denaturation step for $45 \mathrm{~s}$ at $94^{\circ} \mathrm{C}$, a 
Table 1. Greek olive cultivars studied, with code number, main biomorphological characteristics, use of fruits, and geographical origin (Kostelenos, 2006).

\begin{tabular}{|c|c|c|c|c|c|c|c|}
\hline Code & Cultivar name & Fruit weight ${ }^{\mathrm{a}}$ & Productivity ${ }^{b}$ & Oil content ${ }^{\mathrm{c}}$ & Cold resistance $^{d}$ & $\mathrm{Use}^{\mathrm{e}}$ & Origin \\
\hline 1 & Adramitini & 2 & 3 & A & 2 & $\mathrm{~T} / \mathrm{O}$ & Lesvos \\
\hline 2 & Agouromanakolia & 2 & 3 & $\mathrm{H}$ & 3 & $\mathrm{O}$ & Arkadia \\
\hline 3 & Amfissis & 4 & 3.5 & A & 2 & $\mathrm{~T}$ & Amfissa \\
\hline 4 & Amigdalolia & 5 & 3 & A & 1 & $\mathrm{~T}$ & Attiki \\
\hline 5 & Arvanitolia Serron & 4 & 2.5 & $\mathrm{~L}$ & 3 & $\mathrm{~T}$ & Serres \\
\hline 6 & Chondrolia Chalkidikis & 4 & 4 & $\mathrm{~L}$ & 3 & $\mathrm{~T}$ & Chalkidiki \\
\hline 7 & Dafnelia & 3 & 2 & $\mathrm{~L}$ & 2 & $\mathrm{~T} / \mathrm{O}$ & Samos \\
\hline 8 & Gaidourelia & 5 & 3 & $\mathrm{~L}$ & 1 & $\mathrm{~T}$ & Arkadia \\
\hline 9 & Galatistas & 3 & 3.5 & A & 4 & $\mathrm{~T} / \mathrm{O}$ & Chalkidiki \\
\hline 10 & Kalamon & 3 & 2 & $\mathrm{~L}$ & 1 & $\mathrm{~T}$ & Messinia \\
\hline 11 & Kolimbada & 4 & 2 & $\mathrm{~L}$ & 1 & $\mathrm{~T}$ & Messinia \\
\hline 12 & Koroneiki & 1 & 5 & $\mathrm{H}$ & 2 & $\mathrm{O}$ & Messinia \\
\hline 13 & Kothreiki & 3 & 3 & A & 2.5 & $\mathrm{~T} / \mathrm{O}$ & Argolida \\
\hline 14 & Koutsourelia & 1 & 3 & $\mathrm{H}$ & 2 & $\mathrm{O}$ & Ahaia \\
\hline 15 & Lefkolia Serron & 3 & 3.5 & A & 3.5 & $\mathrm{O}$ & Serres \\
\hline 16 & Lianolia Kerkiras & 1 & 3 & A & 2.5 & $\mathrm{O}$ & Kerkira \\
\hline 17 & Maronias & 3 & 3 & $\mathrm{H}$ & 3 & $\mathrm{~T} / \mathrm{O}$ & Komotini \\
\hline 18 & Mastoidis & 2 & 3 & A & 3 & $\mathrm{O}$ & Kriti \\
\hline 19 & Mavrelia Messinias & 1 & 3.5 & A & 2.5 & $\mathrm{O}$ & Messinia \\
\hline 20 & Megaritiki & 3 & 4 & A & 2.5 & $\mathrm{~T} / \mathrm{O}$ & Attiki \\
\hline 21 & Petrolia Serron & 3 & 3 & $\mathrm{H}$ & 2.5 & $\mathrm{~T} / \mathrm{O}$ & Serres \\
\hline 22 & Pierias & 3 & 3 & $\mathrm{H}$ & 3 & $\mathrm{O}$ & Pieria \\
\hline 23 & Throumbolia & 2 & 3 & $\mathrm{H}$ & 1 & $\mathrm{~T} / \mathrm{O}$ & Rodos \\
\hline 24 & Tragolia & 1 & 3 & $\mathrm{H}$ & 2 & $\mathrm{O}$ & Messinia \\
\hline 25 & Valanolia & 3 & 3 & $\mathrm{H}$ & 2.5 & $\mathrm{~T} / \mathrm{O}$ & Lesvos \\
\hline 26 & Vasilikada & 4 & 2 & $\mathrm{~L}$ & 3 & $\mathrm{~T}$ & Evia \\
\hline
\end{tabular}

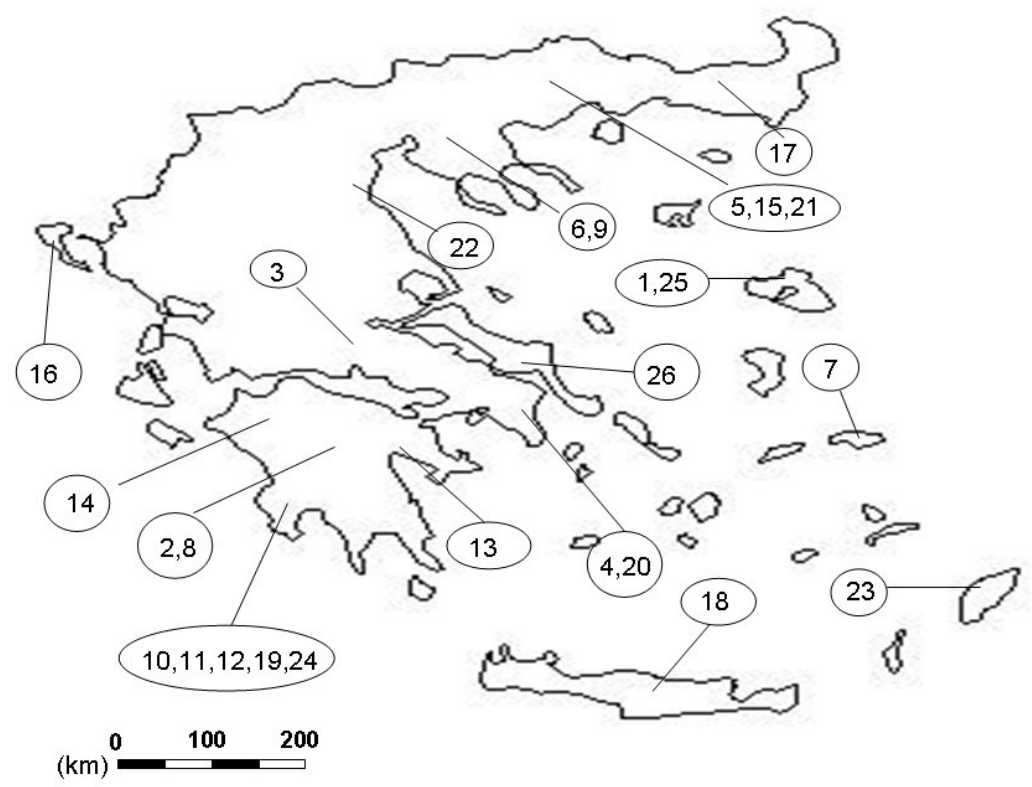

Figure 1. Map of Greece indicating the main area of cultivation of the olive cultivars in this study. The numbers refer to the codes of cultivars shown in Table 1. 
primer annealing step for $45 \mathrm{~s}$ at $50^{\circ} \mathrm{C}$ for DCA-3, $-16,-17$, and -18 , for $45 \mathrm{~s}$ at $55^{\circ} \mathrm{C}$ for DCA- 9 and -10 , for $45 \mathrm{~s}$ at $57^{\circ} \mathrm{C}$ for $\operatorname{UDO} 99(-9,-11$ and -35$)$, for $45 \mathrm{~s}$ at $60^{\circ} \mathrm{C}$ for EMO-3, followed by a primer extension step at $72^{\circ} \mathrm{C}$ for $45 \mathrm{~s}$, and a final extension step at $72^{\circ} \mathrm{C}$ for $8 \mathrm{~min}$.

\begin{tabular}{|c|c|c|c|c|}
\hline Locus & Repeat motif & $\mathrm{Ta}\left({ }^{\circ} \mathrm{C}\right)$ & Forward primer sequence & Reverse primer sequence \\
\hline DCA-3 & $(\mathrm{GA}) 19$ & $50(55)$ & cccaagcggaggtgtatattgttac & tgcttttgtcgtgtttgagatgttg \\
\hline DCA-9 & $(\mathrm{GA}) 23$ & $55(55)$ & aatcaaagtcttccttctcatttcg & gatccttccaaaagtataacctctc \\
\hline DCA-18 & (CA)4CT(CA)3(GA)19 & $50(55)$ & aagaaagaaaaaggcagaattaagc & gttttcgtctctctacataagtgac \\
\hline UDO99-9 & $(\mathrm{AG}) 16$ & $57(57)$ & ttgatttcacattgctgacca & catagggaagagctgcaagg \\
\hline UDO99-35 & (CA) 15 & $57(57)$ & aatttaatggtcacacacac & attgcgaaatagatctacga \\
\hline EMO-3 & $(\mathrm{CA}) 7$ & $60(60)$ & ggtgtagcccaagcecttat & tgcatgaccgtggtgtaagt \\
\hline
\end{tabular}

\section{Electrophoresis}

PCR products were checked by agarose gel electrophoresis and then separated on a gel containing 4.5\% high-resolution agarose, UltraPure ${ }^{\mathrm{TM}}$ Agarose-1000 (Invitrogen). In order to avoid band diffusion and to increase resolution, we used a refrigerated, re-circulating bath (Fisher Scientific, No. 3006) and a horizontal gel electrophoresis unit (Fisher Scientific, No. CHU25), with a built-in cooling block that ensures uniform cooling of the gel. Before applying the electrical current, the bath temperature was adjusted to $-4^{\circ} \mathrm{C}$ and running buffer temperature to $13^{\circ} \mathrm{C}$. Samples were run at $200 \mathrm{~V}$ for $4 \mathrm{~h}$. A 10-bp ladder (Invitrogen) was used as a size standard. Gels were visualized and photographed under UV light with the Molecular Imager ${ }^{\mathbb{B}}$ Gel Doc ${ }^{\mathrm{TM}}$ XR system (Biorad). Images were analyzed with the Quantity 1.0 software (Biorad).

\section{Data analysis}

Polymorphic information content values and heterozygosity $\left(\mathrm{H}_{\mathrm{o}}\right)$ were computed using CERVUS 3.0 (Kalinowski et al., 2007). Probability of identity was calculated by the IDENTITY 1.0 program (Wagner and Sefc, 1999). Amplified alleles were scored for presence (1) or absence (0). Genetic distances were calculated using the Jaccard coefficient of similarity. A dendrogram was constructed via the unweighted pair-group method with arithmetic averages (UPGMA), using the NTSYS-pc program version 2.11e (Rohlf, 2002). A principal coordinate analysis was carried out based on a pairwise, individual-by-individual $(N \mathrm{x} N)$ genetic distance matrix calculated for codominant data, using the GenAlEx 6 software (Peakall and Smouse, 2006). In addition, the SSR data were analyzed by factorial correspondence analysis using the GENETIX 4.0 software. Mantel tests were also performed using the NTSYS program in order to investigate the relationship between the genetic and geographic distances of the cultivars.

\section{RESULTS}

Six SSR loci of the 10 loci originally scored were selected for detailed analysis based on clear amplification products, non-ambiguous scoring data, and efficient detection of polymorphism in the olive germplasm (Khadari et al., 2008). The loci that were excluded were UDO99-11, DCA-16, DCA-17, and DCA-10. The selected SSR loci revealed 81 alleles, ranging from seven at 
the DCA-3 locus (Figure 2) to 20 at the DCA-9 locus (Figure 3), with a mean of 13.5 alleles per locus. Size ranges were as expected (Table 3). Observed heterozygosity ranged from 0.240 at locus DCA-3 to 0.826 at locus UDO99-9, with a mean of 0.600 (Table 3). Polymorphic information content values (Table 3 ) varied from 0.756 (DCA-3) to 0.922 (DCA-9). The probability of sampling identical genotypes differed among loci from 0.019 (UDO99-9) to 0.116 (DCA-18; Table 3). The highest frequencies were observed for alleles $243(36 \%), 221$ (31\%) and $177(23 \%)$ at loci DCA-3, EMO-3 and DCA-18, respectively (Table 4). Allele frequencies based on the estimated null allele frequency were also calculated (Table 4). Analysis of 104 individuals representing 26 cultivars and denominations identified 26 distinct SSR profiles. No intracultivar variability was observed.

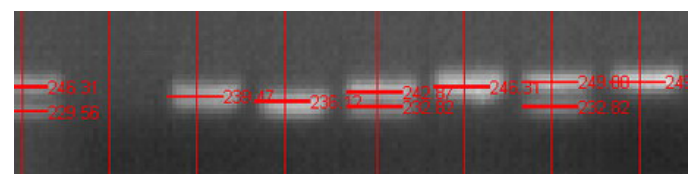

Figure 2. Primer DCA-3 alleles from eight cultivars after scoring with Quantity 1.0.

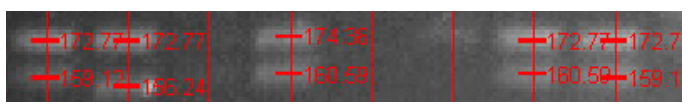

Figure 3. Primer DCA-9 alleles from eight cultivars after scoring with Quantity 1.0.

Table 3. Size range (SR), expected size range (ESR), number of alleles (n), observed heterozygosity $\left(\mathrm{H}_{\mathrm{o}}\right)$, polymorphic information content (PIC), and probability of identity (PI) of microsatellite data for 26 Greek olive cultivars.

\begin{tabular}{lrrrrrr}
\hline Locus & \multicolumn{1}{c}{$\mathrm{SR}$} & $\mathrm{ESR}$ & $\mathrm{n}$ & $\mathrm{H}_{\mathrm{o}}$ & $\mathrm{PIC}$ & PI \\
\hline DCA-3 & $(226-253)$ & $228-250$ & 7 & 0.240 & 0.756 & 0.114 \\
DCA-9 & $(156-238)$ & $161-205$ & 20 & 0.773 & 0.922 & 0.020 \\
DCA-18 & $(142-183)$ & $168-184$ & 15 & 0.615 & 0.116 \\
UDO99-9 & $(83-128)$ & $83-119$ & 19 & 0.826 & 0.919 & 0.019 \\
UDO99-35 & $(131-170)$ & $136-168$ & 11 & 0.750 & 0.880 & 0.045 \\
EMO-3 & $(218-249)$ & $205-215$ & 9 & 0.375 & 0.082 \\
Average & & & 13.5 & 0.597 & $1.65 \times 10^{-5}$ \\
\hline
\end{tabular}

Table 4. Allele size (in bp), allele frequencies (in parentheses) and allele frequencies based on the estimated null allele frequency (in brackets).

\begin{tabular}{cccccc}
\hline DCA-3 & DCA-9 & DCA-18 & UDO99-9 & UDO99-35 & EMO-3 \\
\hline $230(0.02)[0.014]$ & $156(0.14)[0.095]$ & $142(0.04)[0.038]$ & $83(0.04)[0.044]$ & $131(0.05)[0.025]$ & $218(0.08)[0.037]$ \\
$232(0.06)[0.029]$ & $159(0.02)[0.023]$ & $148(0.08)[0.077]$ & $85(0.04)[0.044]$ & $133(0.05)[0.025]$ & $221(0.31)[0.200]$ \\
$237(0.10)[0.058]$ & $162(0.02)[0.023]$ & $151(0.04)[0.038]$ & $87(0.02)[0.022]$ & $140(0.10)[0.105]$ & $224(0.21)[0.115]$ \\
$239(0.18)[0.089]$ & $166(0.05)[0.046]$ & $153(0.08)[0.077]$ & $89(0.07)[0.044]$ & $142(0.18)[0.192]$ & $227(0.10)[0.056]$ \\
$243(0.36)[0.154]$ & $170(0.05)[0.046]$ & $156(0.04)[0.038]$ & $90(0.02)[0.022]$ & $144(0.10)[0.105]$ & $230(0.06)[0.037]$ \\
$245(0.12)[0.044]$ & $172(0.05)[0.046]$ & $159(0.08)[0.077]$ & $91(0.02)[0.022]$ & $147(0.13)[0.133]$ & $233(0.15)[0.115]$ \\
$249(0.16)[0.074]$ & $174(0.02)[0.023]$ & $163(0.04)[0.038]$ & $93(0.02)[0.022]$ & $149(0.10)[0.105]$ & $236(0.02)[0.018]$ \\
- & $181(0.02)[0.023]$ & $165(0.04)[0.038]$ & $97(0.13)[0.140]$ & $152(0.05)[0.051]$ & $240(0.04)[0.037]$ \\
- & $182(0.07)[0.070]$ & $167(0.04)[0.038]$ & $99(0.02)[0.022]$ & $165(0.10)[0.078]$ & $249(0.02)[0.018]$ \\
- & $187(0.05)[0.046]$ & $169(0.04)[0.038]$ & $102(0.02)[0.022]$ & $168(0.13)[0.078]$ & - \\
- & $189(0.07)[0.070]$ & $171(0.04)[0.038]$ & $103(0.04)[0.044]$ & $170(0.03)[0.025]$ & - \\
- & $192(0.05)[0.046]$ & $173(0.08)[0.038]$ & $105(0.07)[0.044]$ & - & - \\
- & $194(0.09)[0.070]$ & $175(0.04)[0.038]$ & $107(0.07)[0.067]$ & - & - \\
- & $200(0.05)[0.046]$ & $177(0.23)[0.118]$ & $109(0.11)[0.091]$ & - & - \\
- & $202(0.14)[0.095]$ & $183(0.12)[0.077]$ & $111(0.13)[0.140]$ & - & - \\
- & $208(0.02)[0.023]$ & - & $113(0.04)[0.044]$ & - & - \\
- & $210(0.05)[0.046]$ & - & $115(0.04)[0.022]$ & - & - \\
- & $217(0.02)[0.023]$ & - & $126(0.07)[0.067]$ & - & - \\
- & $220(0.02)[0.023]$ & - & $128(0.02)[0.022]$ & - & - \\
\hline
\end{tabular}


Clustering according to the UPGMA method revealed five major groups (Figure 4). The first group contained five cultivars (Amfissis, Vasilikada, Galatistas, Lefkolia Serron, Agouromanakolia) two of which (Amfissis, Vasilikada) have large fruits and are used as table olives. Lefkolia Serron and Agouromanakolia are used for oil production, while Galatistas is typically a dual-use cultivar. The second group was the largest, including 12 cultivars (Chondrolia Chalkidikis, Kolimbada, Amigdalolia, Megaritiki, Maronias, Adramitini, Throumbolia, Mastoidis, Kothreiki, Valanolia, Gaidourelia, Arvanitolia Serron). Five were table cultivars (Chondrolia Chalkidikis, Kolimbada, Amigdalolia, Gaidourelia, Arvanitolia Serron) six were dual-use cultivars (Megaritiki, Maronias, Adramitini, Throumbolia, Kothreiki, Valanolia) and one was an oil-producing cultivar (Mastoidis). The third group consisted of the cultivars Koutsourelia and Mavrelia Messinias, which have small fruit that are used for oil production. The fourth group contained cultivars Tragolia, Dafnelia, Lianolia Kerkiras, and Koroneiki. These cultivars are used for oil production, except Dafnelia, which is a dual-use cultivar. The fifth group (Pierias, Petrolia Serron, Kalamon) contained three cultivars, all of which have mediumsized fruits. Pierias is cultivated for oil production, while Petrolia Serron is a dual-use cultivar and Kalamon a table cultivar (Table 1).

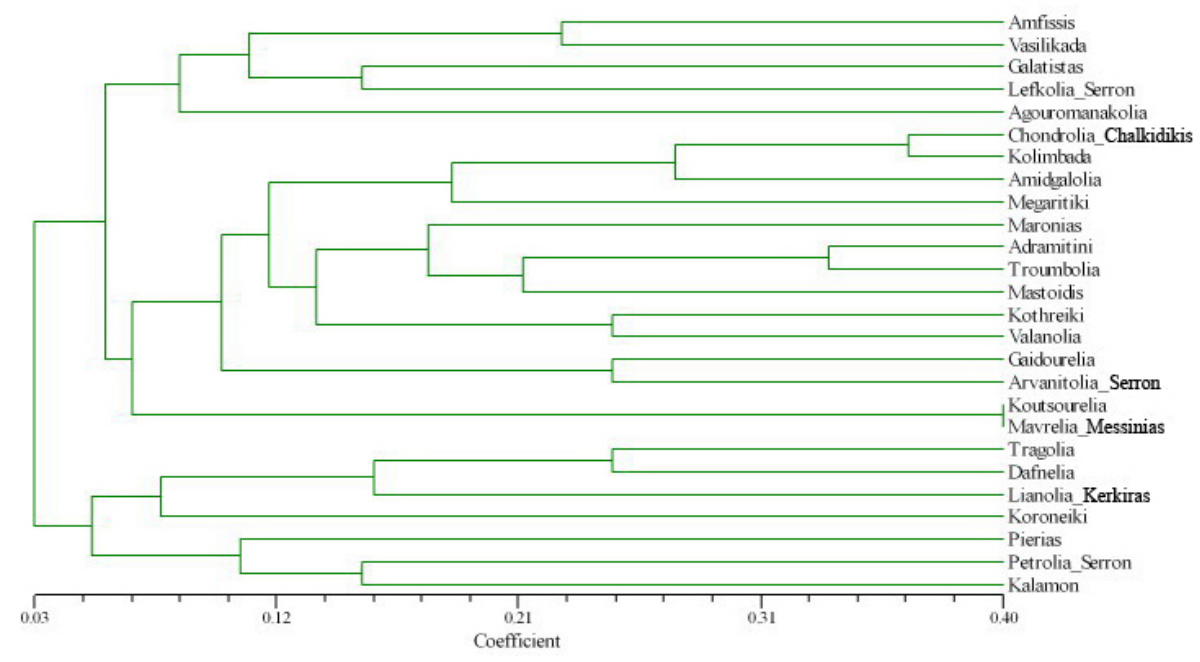

Figure 4. UPGMA dendrogram obtained from microsatellite data for Greek olive cultivars.

The principal coordinate analysis results revealed that a considerable amount of variation (61\%) was explained by the first three axes. Axes 1, 2 and 3 explained 24, 20 and 17\% of the variation, respectively. Five loosely defined groups were also identified and grouping results based on principal coordinate analysis (Figure 5) were similar to dendrogram clustering using UPGMA. A single difference in grouping between principal coordinate analysis and UPGMA was observed regarding cultivars Koutsourelia and Mavrelia Messinias. The above cultivars grouped together in the third group of UPGMA, but did not cluster in principal coordinate analysis. 


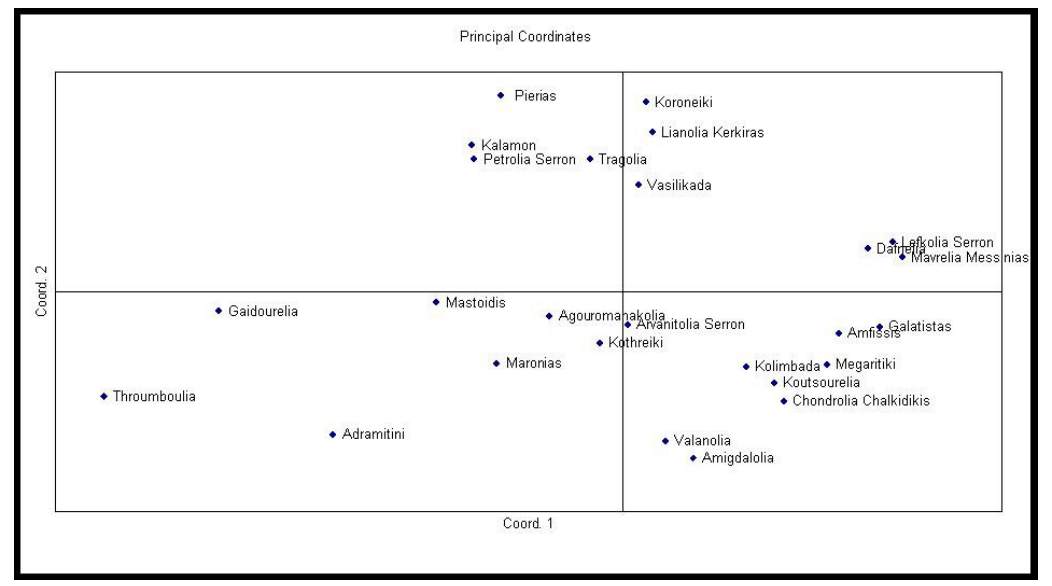

Figure 5. Principal coordinate analysis derived from 81 microsatellite alleles.

The first three axes of the factorial correspondence analysis explained $23.08 \%$ of the total variability. The multivariate analysis gave more abstract grouping than UPGMA and principal coordinate analysis depicted two main groups (Figure 6), a large one (20 cultivars) and a small one (four cultivars). Three cultivars (Throumbolia-code 23, Tragolia-code 24, Vasilikada-code 26) were placed separately.

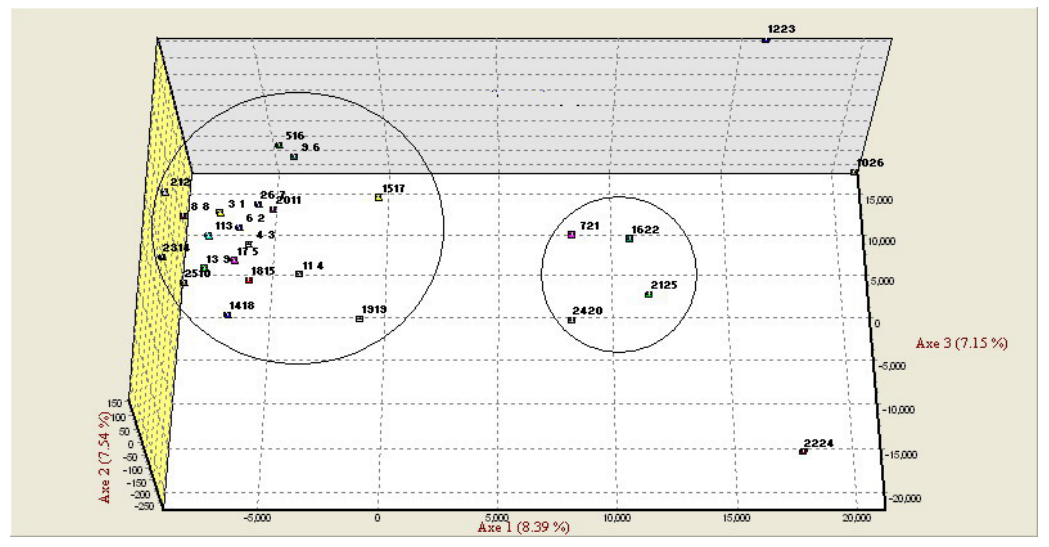

Figure 6. Factorial correspondence analysis based on SSR data. Last digits correspond to the cultivar code in Table 1. The first or first two digits correspond to a random cultivar number.

Genetic and geographic distance differences among cultivars were not concordant, based on the Mantel test $(r=0.03, P=0.29)$. Additional Mantel tests that considered the southern and northern Greek cultivars separately also indicated a lack of significant correlation ( $\mathrm{r}$ $\leq 0.01, \mathrm{P} \geq 0.50$ ). 


\section{DISCUSSION}

A set of 26 Greek olive denominations were genotyped at six SSR loci in order to examine genetic variation at the molecular level. In general, our results were in agreement with those of Baldoni et al. (2009), regarding locus stability and usage. Allele numbers and sizes were also within the range in previous studies (Baldoni et al., 2009). Relatively few SSR loci were used; nevertheless, most were highly polymorphic and therefore allowed unequivocal identification of all the plant material. Previous studies (Besnard et al., 2008; Gomes et al., 2009) also discriminated cultivar collections using six SSR loci. The selected loci, due to the easily interpretable alleles on high-resolution agarose gels, can be used by laboratories that do not have access to automated sequencers or silver-staining polyacrylamide gels. Markers DCA-9, DCA-18 and UDO99-9 in particular were highly polymorphic and sufficient to discriminate all cultivars. These markers would be suitable for DNA fingerprinting of Greek olive cultivars. On the other hand, four SSR loci were excluded from our study because of unfavorable characteristics, such as absence of stability and repeatability, non-interpretable fingerprinting patterns, low degree of polymorphism, and few alleles. A non-interpretable fingerprinting pattern associated with multiple locus amplification was observed at locus DCA-10. This pattern could be due to duplication of a particular genomic region (Rallo et al., 2000). Markers UDO99-11, DCA-16 and DCA-17 were deemed unsuitable because they were not highly polymorphic, presenting few alleles in these Greek genotypes (two alleles for UDO99-11 and three for DCA-16 and DCA-17).

Microsatellite loci DCA-9, UDO99-9, DCA-18, UDO99-35, EMO-3, and DCA-3 revealed 20,19,15, 11, 9, and 7 alleles, respectively (Table 3 ). This large number of alleles per locus may have been influenced by the sampling strategy, as most cultivars and denominations were selected from diverse areas of cultivation. The mean number of alleles per locus observed in our study $(\mathrm{A}=13.50)$ is similar to the value obtained from a Mediterranean variety collection ( $\mathrm{A}=14.50$; Breton et al., 2008), using 12 DCA primers. Mean heterozygosity was high, indicating a wealth of genetic variation in the cultivar collection. Similar heterozygosity values for the same SSR primers in O. europaea have been reported (Khadari et al., 2008). Polymorphic information content classified all SSR loci as both informative and suitable for mapping (polymorphic information content $>0.70$; Poljuha et al., 2008). The total exclusion probability $(\mathrm{P}>0.99)$ and the total probability of identity $\left(\mathrm{P}>1.65 \times 10^{-5}\right)$ indicate that the chance of finding two individuals with the same genotype in the population is almost zero.

Allele frequencies were generally low, particularly at loci with a high allelic number, as expected. Differences between observed allele frequencies and allele frequencies based on the estimated null allele frequency were not statistically significant (Table 4). Null alleles arise when mutations occur in the annealing site, preventing one or both of the primers from binding (Pemberton et al., 1995). In our study, null alleles did not alter the overall outcome of assignment testing. Therefore, the six SSR loci could be deemed as appropriate for this type of study based on this property as well. Unequivocal identification of all entries and absence of any intra-denomination variability support the notion that all northern Greek denominations represent distinct olive cultivars.

No particular clustering was observed among cultivars from northern Greece, based both on principal coordinate analysis and the UPGMA dendrogram. For example, two cultivars (Galatistas, Lefkolia Serron) of the seven from northern Greece were included in the first 
group. Chondrolia Chalkidikis, Arvanitolia Serron and Maronias were placed in the second group, while Pierias grouped with Petrolia Serron in the fifth group (Figure 4). The graphical representation of the first two principal coordinates, which explained $44 \%$ of the total variability, also showed that northern Greek cultivars are scattered in the different groups (Figure 5). Factorial correspondence analysis defined two major groups in three-dimensional space, where $23.08 \%$ of the total variability was explained. This value was not particularly high, but is within the range of similar studies (Breton et al., 2008; Zitoun et al., 2008). In the northern Greek cultivars, factorial correspondence analysis results agreed with the outcome of principal coordinate analysis and UPGMA, as these were not associated with a particular group. Therefore, the hypothesis that northern Greek cultivars form a distinctive group is not supported by either univariate or multivariate analyses. Mantel tests did not show correlation between geographic and genetic distances. The present distribution of olive cultivars in Greece clearly appears to be the result of strong anthropogenic influences. This finding is in agreement with previous studies on Greek olive cultivars (Nikoloudakis et al., 2003; Hagidimitriou et al., 2005).

Several molecular studies have discriminated various Greek olive cultivars (Fabbri et al., 1995; Besnard et al., 2000, 2001a,b; Belaj et al., 2001, 2002; Nikoloudakis et al., 2003; Rallo et al., 2003; Owen et al., 2005; Terzopoulos et al., 2005; Hagidimitriou et al., 2005; Montemurro et al., 2005; Díaz et al. 2006b; Essadki et al., 2006; Omrani-Sabbaghi et al., 2007; Bracci et al., 2009). Greek genotypes seem to carry the same chloroplast DNA polymorphisms (Besnard et al., 2000) and the same mitotypes (ME1), except Amigdalolia, which carries the ME2 mitotype (Besnard et al., 2001b). However, mitotypes and chlorotypes are less efficient in discriminating cultivars compared to other markers (Besnard et al., 2001a). Four previous studies (Belaj et al., 2001, 2002; Besnard et al., 2001a,b) have analyzed Greek cultivars along with other Mediterranean cultivars using RAPD markers; none of them found a particular clustering among the Greek cultivars. Most of the genetic diversity was found to be attributable to differences among genotypes within a country. Belaj et al. (2002), Terzopoulos et al. (2005) and Essadki et al. (2006) observed various groupings of Greek cultivars based on ISSR markers. Omrani-Sabbaghi et al. (2007) did not find any particular clustering between seven Greek genotypes using SSR markers. Fabbri et al. (1995), using RAPD markers, Rallo et al. (2003) using SSR markers, Montemurro et al. (2005) using SSR and AFLP markers, and Bracci et al. (2009) using SSR markers, included only two Greek genotypes in their studies from which no relevant information could be deduced. Discrimination of Greek olive cultivars according to SSR marker analysis does not produce clusters similar to those resulting from ISSR (Terzopoulos et al., 2005) and RAPD (Nikoloudakis et al., 2003; Hagidimitriou et al., 2005) analyses. On the contrary, our dendrogram presents similarities with the dendrograms reported in previous AFLP marker-based studies (Hagidimitriou et al., 2005; Owen et al., 2005). For example, Megaritiki, Kolimbada, Adramitini, Kothreiki, and Amigdalolia are grouped together in our study, as in the Hagidimitriou et al. (2005) AFLP study. Moreover, Koroneiki, Tragolia, Dafnelia grouped together in our study, as in the AFLP study conducted by Owen et al. (2005).

Greek olive cultivars have been traditionally classified according to their fruit size and consequently their usage, since size and fruit use are in most cases interdependent. Cultivars that produce large fruits are used mainly as table olives, while small-fruited cultivars are used mainly for olive oil production. Previous molecular studies reported genetic distance clustering of olive cultivars according to their fruit size and usage (Loukas and Krimbas, 1983; Fabbri et al., 1995; Besnard et al., 2001b; Nikoloudakis et al., 2003; Hagidimitriou et al., 2005). It 
is possible that this diversity resulted from selection pressure for desirable traits (fruit size, oil content). However, in our study, as in Belaj et al. (2001), only a weak concordance of cultivar classification to fruit size and usage was observed.

In conclusion, after testing our hypotheses, we have shown that the northern Greek cultivar denominations that we investigated represent distinctive olive cultivars. However, these northern Greek cultivars do not seem to form a distinct genetic group, when compared to a collection of typical Greek olive cultivars. This is the first study on DNA fingerprinting of Greek olive cultivars using microsatellite markers. Although the major cultivated genotypes that cover most of the Olea cultivation range in Greece have been fingerprinted, further study is needed in order to elucidate the variation and genetic structure of the Greek olive tree genome in order to conserve olive germplasm cultivated in restricted areas. This research should be useful for breeding programs, for nurseries dealing with olive cultivar propagation and dissemination and subsequently for commercialization of olives and related products.

\section{ACKNOWLEDGMENTS}

Research supported by the Hellenic State Scholarship Foundation and the Alexander Technological Educational Institute of Thessaloniki. We acknowledge the contributions of Professor A. Roubos and Mr. G. Kostelenos.

\section{REFERENCES}

Baldoni L, Cultrera NG, Mariotti R, Ricciolini C, et al. (2009). A consensus list of microsatellite markers for olive genotyping. Mol. Breed. 24: 213-231.

Banilas G, Minas J, Gregoriou C, Demoliou C, et al. (2003). Genetic diversity among accessions of an ancient olive variety of Cyprus. Genome 46: 370-376.

Belaj A, Trujillo I, De la Rosa R and Rallo L (2001). Polymorphism and discriminating capacity of randomly amplified polymorphic markers in an olive germplasm bank. J. Am. Soc. Hort. Sci. 126: 64-71.

Belaj A, Satovic Z, Rallo L and Trujillo I (2002). Genetic diversity and relationships in olive (Olea europaea L.) germplasm collections as determined by randomly amplified polymorphic DNA. Theor. Appl. Genet. 105: 638-644.

Besnard G, Khadari B, Villemur P and Bervillé A (2000). Cytoplasmic male sterility in the olive (Olea europaea L.). Theor. Appl. Genet. 100: 1018-1024.

Besnard G, Breton C, Baradat P, Khadari B, et al. (2001a). Cultivar identification in olive based on RAPD markers. J. Am. Hort. Sci. 126: 668-675.

Besnard G, Baradat P and Bervillé A (2001b). Genetic relationships in the olive (Olea europaea L.) reflect multilocal selection of cultivars. Theor. Appl. Genet. 102: 251-258.

Besnard G, Garcia-Verdugo C, De Casas RR, Treier UA, et al. (2008). Polyploidy in the olive complex (Olea europaea): evidence from flow cytometry and nuclear microsatellite analyses. Ann. Bot. 101: 25-30.

Bracci T, Sebastiani L, Busconi M and Fogher C (2009). SSR markers reveal the uniqueness of olive cultivars from the Italian region of Liguria. Sci. Hortic. 122: 209-215.

Breton C, Pinatel C, Medail F and Bonhomme F (2008). Comparison between classical and Bayesian methods to investigate the history of olive cultivars using SSR-polymorphisms. Plant. Sci. 175: 524-532.

Carriero F, Fontanazza G, Cellini F and Giorio G (2002). Identification of simple sequence repeats (SSRs) in olive (Olea europaea L.). Theor. Appl. Genet. 104: 301-307.

Cipriani G, Marrazzo MT, Marconi R, Cimato A, et al. (2002). Microsatellite markers isolated in olive (Olea europaea L.) are suitable for individual fingerprinting and reveal polymorphism within ancient cultivars. Theor. Appl. Genet. 104: 223-228.

De La Rosa R, James CM and Tobutt KR (2002). Isolation and characterization of polymorphic microsatellites in olive (Olea europaea L.) and their transferability to other genera in the Oleaceae. Mol. Ecol. Notes 2: 265-267.

Díaz A, Martín A, Rallo P and De la Rosa R (2006a). Self- and cross incompatibility mechanisms: a strategy to ensure a 
great variability in olive (Olea europaea L.) populations. Olea 25: 29-33.

Díaz A, De la Rosa R, Martín A and Rallo P (2006b). Development, characterization and inheritance of new microsatellites in olive (Olea europaea L.) and evaluation of their usefulness in cultivar identification and genetic relationship studies. Tree Genet. Genomes 2: 165-175.

Essadki M, Ouazzani N, Lumaret R and Moumni M (2006). ISSR variation in olive-tree cultivars from Morocco and other Western Countries of the Mediterranean Basin. Genet. Resour. Crop Evol. 53: 475-482.

Fabbri A, Hormaza JI and Polito VS (1995). Random amplified polymorphic DNA analysis of olive (Olea europaea L.) cultivars. J. Am. Soc. Hortic. Sci. 120: 538-542.

Gomes S, Martins-Lopes P, Lopes J and Guedes-Pinto H (2009). Assessing genetic diversity in Olea europaea L. using ISSR and SSR markers. Plant. Mol. Biol. Rep. 27: 365-373.

Hagidimitriou M, Katsiotis A, Menexes G, Pontikis C, et al. (2005). Genetic diversity of major Greek olive cultivars using molecular (AFLPs and RAPDs) markers and morphological traits. J. Am. Soc. Hortic. Sci. 130: 211-217.

Ipek A, Barut E, Gulen H, Oz AT, et al. (2009). SSR analysis demonstrates that olive production in the southern Marmara region in Turkey uses a single genotype. Genet. Mol. Res. 8: 1264-1272.

Kalinowski ST, Taper ML and Marshall TC (2007). Revising how the computer program CERVUS accommodates genotyping error increases success in paternity assignment. Mol. Ecol. 16: 1099-1106.

Khadari B, Charafi J, Moukhli A and Ater M (2008). Substantial genetic diversity in cultivated Moroccan olive despite a single major cultivar: a paradoxical situation evidenced by the use of SSR loci. Tree Genet. Genomes 4: 213-221.

Kostelenos G (2006). Registry and Geographical Distribution of Greek Olive Cultivars (in Greek). Evripos Publ, Athens, 1-22.

Loukas M and Krimbas CB (1983). History of olive cultivars based on their genetic distances. J. Hortic. Sci. 58: 121-127.

Montemurro C, Simeone R, Pasqualone A and Ferrara E (2005). Genetic relationships and cultivar identification among 112 olive accessions using AFLP and SSR markers. J. Hortic. Sci. Biotech. 80: 105-110.

Nikoloudakis N, Banilas G, Gazis F and Hatzopoulos P (2003). Discrimination and genetic diversity among cultivated olives of Greece using RAPD markers. J. Am. Soc. Hortic. Sci. 128: 741-746.

Omrani-Sabbaghi A, Shahriari M, Falahati-Anbaran M, Mohammadi AS, et al. (2007). Microsatellite markers based assessment of genetic diversity in Iranian olive (Olea europaea L.) collections. Sci. Hortic. 112: 439-447.

Owen CA, Bita EC, Banilas G, Hajjar SE, et al. (2005). AFLP reveals structural details of genetic diversity within cultivated olive germplasm from the Eastern Mediterranean. Theor. Appl. Genet. 110: 1169-1176.

Peakall R and Smouse PE (2006). GENALEX 6: genetic analysis in Excel. Population genetic software for teaching and research. Mol. Ecol. Notes 6: 288-295.

Pemberton JM, Slate J, Bancroft DR and Barrett JA (1995). Nonamplifying alleles at microsatellite loci: a caution for parentage and population studies. Mol. Ecol. 4: 249-252.

Poljuha D, Sladonja B, Šetić E and Milotić A (2008). DNA fingerprinting of olive varieties in Istria (Croatia) by microsatellite markers. Sci. Hortic. 115: 223-230.

Rallo P, Dorado G and Martín A (2000). Development of simple sequence repeats (SSRs) in olive tree (Olea europaea L.). Theor. Appl. Genet. 101: 984-989.

Rallo P, Tenzer I, Gessler C, Baldoni L, et al. (2003). Transferability of olive microsatellite loci across the genus Olea. Theor. Appl. Genet. 107: 940-946.

Rohlf FJ (2002). Numerical Taxonomy and Multivariate Analysis System, Version 2.11e. Exeter Software, Setauket, NY.

Sarri V, Baldoni L, Porceddu A, Cultrera NG, et al. (2006). Microsatellite markers are powerful tools for discriminating among olive cultivars and assigning them to geographically defined populations. Genome 49: 1606-1615.

Sefc KM, Lopes MS, Mendonça D and Rodrigues Dos Santos M (2000). Identification of microsatellite loci in olive (Olea europaea) and their characterization in Italian and Iberian olive trees. Mol. Ecol. 9: 1171-1173.

Terzopoulos PJ, Kolano B, Bebeli PJ and Kaltsikes PJ (2005). Identification of Olea europaea L. cultivars using intersimple sequence repeat markers. Sci. Hortic. 105: 45-51.

Wagner HW and Sefc KM (1999). Identity 1.0. Software for the analysis of microsatellite data. Centre for Applied Genetics, University of Agricultural Sciences, Vienna.

Zitoun B, Bronzini de Caraffa V, Giannettini J, Breton C, et al. (2008). Genetic diversity in Tunisian olive accessions and their relatedness with other Mediterranean olive genotypes. Sci. Hortic. 115: 416-419. 